\title{
The Role and Potential of Social Worker Involvement in Hospital Emergency Departments: A Practice-Based Scoping Review
}

\author{
Johann Bell \\ Emergency Department \& Sexual Assault Response Team, Logan \& Beaudesert Hospitals, \\ Metro South Health, Queensland, Australia
}

Brett Davies

Department of Social Work, Logan \& Beaudesert Hospitals, Metro South Health, Queensland, Australia

Claire Walsh

Department of Social Work, Logan Hospital, Metro South Health, Queensland, Australia

Hannah Knowlman

Department of Social Work, Caboolture \& Kilcoy Hospitals, Metro North Health, Queensland, Australia

Tina Hefford (passed away)

Pim Kuipers (Corresponding Author)

Centre for Functioning and Health Research, Metro South Health, and

The Hopkins Centre, Griffith University, Queensland, Australia

Received: August 6, 2018 Accepted: October 2, 2018 Published: October 4, 2018

doi:10.5296/ijsw.v5i2.13472 URL: http://doi.org/10.5296/ijsw.v5i2.13472 


\section{Abstract}

Background: Social worker input into hospital emergency department (ED) services would appear to be central to the provision of effective, durable and comprehensive services. Unfortunately, there are few literature overviews to summarise this potential.

Methods: A practice-based scoping review was conducted to identify the role and potential of social worker involvement in emergency department settings. After initial screening, abstracts of 252 articles were read and screened, resulting in 37 articles, which were reviewed and thematically analysed by pairs of reviewers, and also appraised for quality and relevance.

Results: Three key practice areas of social work involvement in emergency departments were identified: mental health, suicide risk and crisis, and chronic disease. Details of social work involvement in each key practice area as noted in the literature were outlined. Beyond this, two priority focus areas were also noted: social work screening and assessment in ED, and developing a social work model that is relevant to ED.

Conclusion: The identified key practice areas and priority focus areas provide a useful guide for practitioners (to more clearly define their assistance and interventions in ED), and for managers and academics (to more clearly guide the development of social work policy, practice and staffing models in ED settings).

Keywords: Emergency department, Hospital services, Social work role, Scoping review

\section{Introduction}

The health care sector in Australia and internationally is responding to policy reforms aimed at increasing safety, care outcomes and patient satisfaction whilst reducing, or at least managing, service costs. In response health services are redefining service scope, and health practitioners, including social workers are having to competitively identify competency and value. At the same time there is pressure to broaden the scope and expertise of service roles. Increasingly the focus and range of services provided by health care providers is narrowing towards concentrating on safe and effective responses to clearly identified health conditions.

In this context, hospital social work is in a state of flux and change (McMichael, 2000). Within the profession there is increasing requirement for hospital social workers to demonstrate that their work reflects best practice and current evidence (Moriarty \& Manthorpe, 2016). Within hospitals and among healthcare professionals, there is often confusion as to the role of social workers, their relationships with other professionals, and there are often inappropriate work assignments and referrals (McMichael, 2000). One way to provide greater clarity in such a context is to identify key practice issues from existing research through a review of relevant literature. In particular, in contexts of complexity and ambiguity, scoping reviews, with their broad inclusion criteria and methodological breadth are likely to be most meaningful (Moriarty \& Manthorpe, 2016).

Social work interventions occur across the spectrum of service delivery, including in hospital emergency departments (ED). In such settings, social workers provide counselling, information, support, referral, community resource linking, discharge planning, advocacy and other key services (McClennen, Keys, \& Day, 2016; Moore, Ekman, \& Shumway, 2012). Within the current environment of healthcare service and workforce reforms the role of social workers in ED settings is under review, and other professionals are increasingly advocating to 
fulfil such functions (Ryan, Clemmett, \& Snelson, 1997; Wand, White, \& Patching, 2010, 2011).

However, many patients who frequent hospital emergency departments have complex needs and multiple unmet medical, psychological, behavioural and social concerns; they often have fewer personal resources, sometimes with inadequate support from community service providers (Meng, Muggli, Baetz, \& D'Arcy, 2017; Pines et al., 2011). As such, social workers would appear to be central to meeting the needs of such patients, but unfortunately there is limited research examining the utility of social work services in ED settings (Moore et al., 2012).

To more fully document relevant research, we chose to conduct a scoping review to document existing social work interventions and expectations, and explore potential roles of social workers in hospital emergency departments. In this review we also sought to engage social work practitioners in critical appraisal of research and to synthesise practical evidence which is fit-for-purpose for social work practice and planning.

An important means of establishing evidence in social work and related areas is to conduct some form of review or overview of the literature (Fitzgerald et al., 2017; Rozas \& Klein, 2010). For this review, the team chose a scoping review methodology (Arksey \& O'Malley, 2005), acknowledging that these are suited to collaborative or team-based approaches (Levac, Colquhoun, \& O'Brien, 2010). Scoping reviews are rigorous surveys of the literature to identify key concepts, and describe the nature of evidence on a topic (Arksey \& O'Malley, 2005). Within the scoping review process, literature within a defined set is identified through a bibliographic data base search, screened for alignment with the research question, summarized, and then thematically analysed to determine key issues. Such reviews have been used in a range of health and welfare settings, and found to be particularly useful for identifying available evidence and noting research gaps, particularly in complex or emerging areas (Anderson, Allen, Peckham, \& Goodwin, 2008; Arksey \& O'Malley, 2005), and suited to team collaborations (Levac et al., 2010).

Recognising that the available literature on this issue was mixed, it was agreed that it would be beneficial to prioritise findings such that the highest quality and most clinically relevant publications would have the greatest weight of evidence in the review (Ogilvie et al., 2008). Consequently it was determined that the traditional scoping review methodology would be adapted to incorporate a rating of the quality and relevance of each included article (Daudt, Van Mossel, \& Scott, 2013). The review was conducted as a practice-based research initiative, led by five social work practitioners working with an experienced research mentor (Daudt et al., 2013; Fitzgerald et al., 2017).

The social workers undertaking this scoping review were working within an outer-metropolitan public hospital in one of Australia's state capital cities. The local area serviced by the hospital had been undergoing significant population growth which is now at 313,785 residents. In response to this population growth, the hospital has grown from a 48-bed hospital in 1990 to comprise 448 beds presently and remains substantially under resourced in acute beds for population needs. The hospital's emergency department is the second busiest (often the busiest) in its state. The population serviced by the hospital is culturally diverse and socially disadvantaged with resultant high levels of psychosocial 
complexity and risk for many patients accessing health care. For example, some 72,609 (26.1\%) of residents are born overseas and $12.8 \%$ speak a language other than English at home. Socioeconomically, $31.1 \%$ of the population falls within the most disadvantaged quintile, whilst $17.6 \%$ of families have no parent employed and $19.4 \%$ are one-parent families.

\section{Methods}

We adapted a number of steps from existing frameworks (Arksey \& O'Malley, 2005), which are presented in diagram form (Figure 1).

The research team (six people) met as a whole to discuss their interest in the topic and formulate a research question. Recognising that traditional PICO format (Patient, Intervention, Comparison, and Outcome) was not relevant to the nature of this issue a more general research question was established. This was stated as "What is the role and potential of social worker involvement in hospital emergency departments?".

1) Based on the question, a number of search terms were considered and trial searches were undertaken on CINAHL, PsycINFO and SocINDEX bibliographic databases. Table 1 outlines the search terms utilised. With application of limiters regarding: time frame (previous 20 years), context and journal type, the database search yielded 740 'hits'.

Table 1. Agreed search terms

\begin{tabular}{ll}
\hline Category & Search terms selected \\
\hline Service Context & Emergency department OR Emergency service OR ED \\
AND & AND \\
Discipline Focus & Social Work \\
AND & AND \\
Activity Focus & Assessment OR Crisis Intervention OR Crisis Management \\
\hline
\end{tabular}

2) All titles were read by two team members independently. Any titles which appeared to have some potential relevance to the research question were included and the abstract was retrieved. There were 443 articles excluded at title level.

3) After removal of duplicates (3), the abstracts of all 294 hits were read by two team members, who screened them for alignment with the research question. This resulted in 252 articles being excluded on the basis of a consensus decision between two team members in reference to the research question.

4) The remaining 42 articles were retrieved and downloaded. Each was also read by two team members independently. They undertook a process of thematic analysis of the key themes of each article. They documented key points, quotes, findings or conclusions that pertained to the research question, and also ranked each article on quality and relevance, (Appendix 1). Five additional articles were excluded at this point, found not to be relevant. Each pair of reviewers then discussed their ratings and established consensus on a final rating of quality and relevance for each article. 


\section{$\Lambda$ Macrothink}

International Journal of Social Work

ISSN 2332-7278

2018, Vol. 5, No. 2

5) Based on a consensus process, researchers worked in pairs to compare their key points, summaries and conclusions for each article. In cases of discrepancy the pair met together, returned to the article and noted their respective points and rationale. Final conclusions were then agreed for each article. Each was also categorised according to the three levels of relevance and quality (Figure 1). There were no instances of discrepancy after initial discussions.

6) In a three stage collating and summarising exercise, all team members met together with their respective summaries and key points from each of the higher quality and higher relevance articles. Potential categories encompassing these findings were discussed within the team to ensure congruence. In the second stage, the team extracted key points from each of the high quality and relevance articles, thematically grouping issues identified. In the third stage, the team used this thematic structure to include any other information drawn from articles that were classified as intermediate level. Finally notes from lower level quality and relevance articles were also included in the structure where relevant. In this way the information obtained from higher quality and relevance articles had the greatest prominence in the derived evidence.

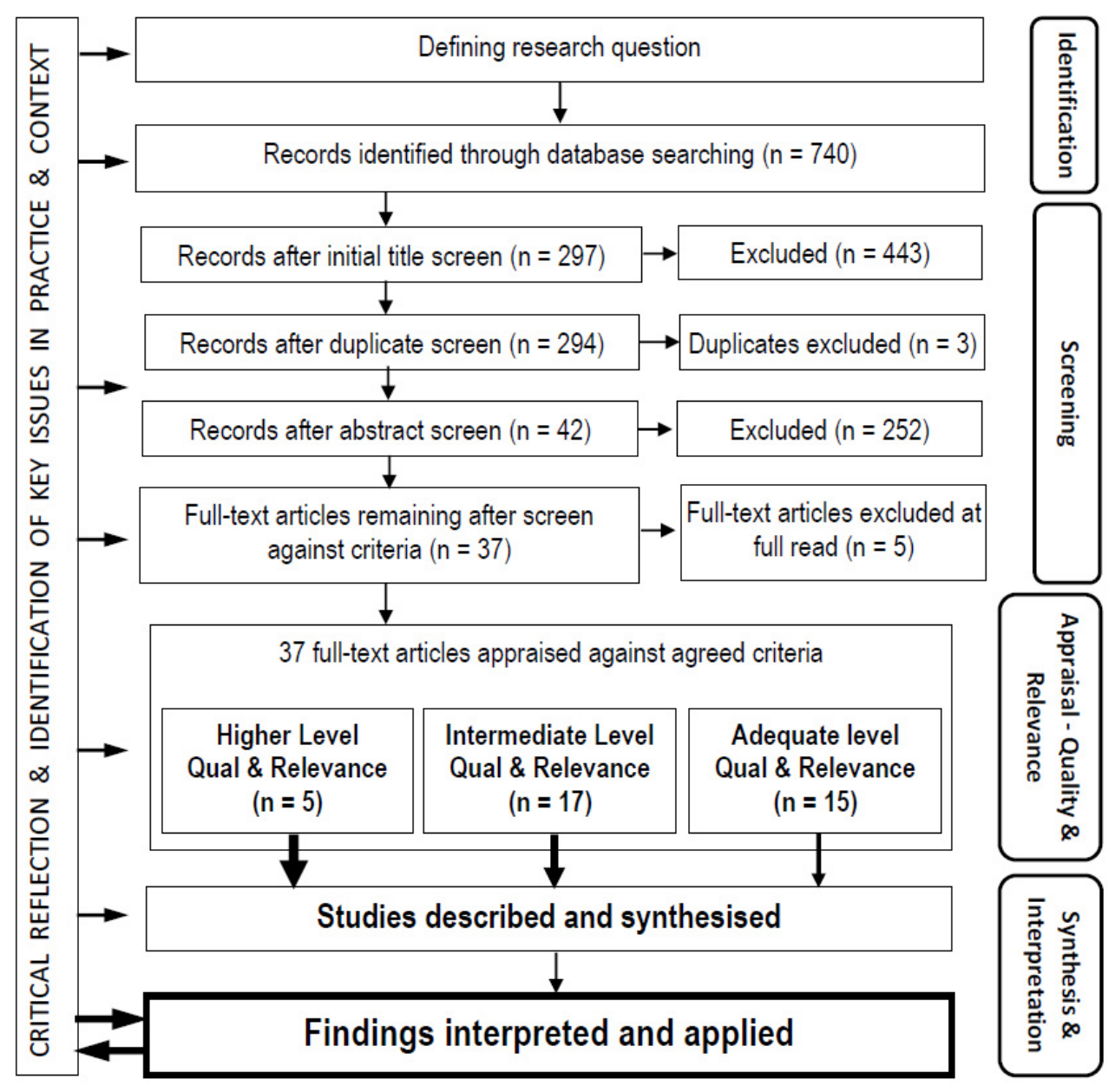

Figure 1. Flow diagram of practice based scoping review 


\section{Results and Discussion}

Thematic analysis of the literature identified in the current review reflected a number of areas in which social worker involvement in ED benefits the patient and their family, other professionals, and the broader health system. First, the review provided a detailed description of the role of social workers in ED. Second, it identified three key practice areas for social workers in this context, namely: mental health, suicide risk and crisis intervention, and chronic disease. Third, the review drew from the literature to identify two important priority focus areas for social work in ED: the need for greater social work screening and assessment in ED settings, and the need for a social work practice model that is relevant to ED. While the key practice areas describe existing patient groups for whom social work intervention in ED has been seen as vital, the priority focus areas identify priorities for the expansion and consolidation of social work in ED. These themes provide a very useful overview of the relevant literature, which may contribute to the expansion of the role of social work in ED.

\subsection{Role of Social Workers}

Reviewed articles noted the vital role of social workers in complex ED admissions (Mason \& Auerbach, 2009), in cases where patients are intoxicated or addicted (McCormack et al., 2013), or where admissions are involuntary (Lindsey, Joe, Muroff, \& Ford, 2010). In crisis situations, they play a strategic role in the transition from emergency services to outpatient services while ensuring the patient remains safe (Lizardi \& Stanley, 2010). Social workers provide a key service in responding to both the immediate clinical response to psychosocial needs, and a central role in the patient's navigation through a highly complex service system which often has a diverse range of patient care stakeholders who are both internal and external to the ED. Based on their skills and knowledge in goal setting, family/carer system engagement, knowledge of what is available via a range of external service providers, and understanding of clinical roles and care process within the ED environment, social workers often undertake the core task of coordinating immediate responses to complex psychosocial needs and planning for aftercare post discharge.

Increasingly emergency departments provide treatment for the disenfranchised, the homeless with no social support, the mentally ill, and those who have little or no insurance or do not know how to access "routine" care (Kelly, 2005). Reviewed articles reflected the key role social workers play when patients' social and contextual problems impact their medical problems (Mason \& Auerbach, 2009). Social workers contribute to ED processes in many ways, including identifying facts and issues that are important for understanding and handling a patient (Räsänen, 2012). Importantly, social workers can be vital advocates for both the patient and family members in the ED setting, for example, facilitating visitation by close family or friends, which evidence has shown can reduce the severity of PTSD in the aftermath of a potentially traumatic event (Lubomirsky et al., 2014). Social workers also advocate for patient rights and ensure they and their families are involved in their care and treatment and promote self management where possible (Hill, Joubert, \& Epstein, 2013). Good communication and patient involvement in care reduces assumptions being made, and enhances a patient's self-determination around their illness (Kelly, 2005).

In particular, the review noted that social workers play a key role in patient discharge and transition from the ED (Cleak \& Turczynski, 2014). The skills and capacity of social workers 
to connect patients with community supports, to assist with relationship issues, and to facilitate practical social and contextual outcomes (Joubert, Lee, McKeever, \& Holland, 2013; Mason \& Auerbach, 2009), makes their contribution to the ED setting vital. These community connections reduce psychological and social deterioration which has been shown to contribute to ill health (Auerbach \& Mason, 2010; Cleak \& Turczynski, 2014), this is particularly so in the transition to ambulatory (or outpatient) care (Cleak \& Turczynski, 2014); a context where patients require facilitation and coordination of numerous forms of support, coordination, care and assistance (Mason \& Auerbach, 2009).

Reviewed studies also suggested that by assisting patients, and especially older patients with complex social and medical conditions, social workers contribute to reducing the number and length of hospital admissions (Mason \& Auerbach, 2009). Indeed it has been noted that social workers can improve treatment outcomes as well as decrease rates of overutilization and costs in emergency department settings through the application of standard social work strategies such as case management, psycho-education, follow-up, and motivational interventions (Alonzo, Stanley, Cournos, \& Goldfinger, 2013; Wells, Lagomasino, Palinkas, Green, \& Gonzalez, 2013).

Beyond these general dimensions, some key practice areas were specifically identified in the reviewed studies. These are outlined below. Appendix 2 provides an overview of the articles reviewed.

\subsection{Key Practice Area - Mental Health}

Literature included in the current review noted that individuals who experience psychological or mental health issues, or those who have health conditions exacerbated by mental health concerns, often present to ED for assessment and support (Baraff, Janowicz, \& Asarnow, 2006; Clarke, Usick, Sanderson, Giles-Smith, \& Baker, 2014; Hill et al., 2013). The complexity of issues around mental health presentations in ED was evident across the reviewed literature. Mental health problems make up 15\% of ED presentations (Clarke et al., 2014; Goode, Melby, \& Ryan, 2014), and patients who present to ED with mental health concerns have substantially increased lengths of stay, compared with others (Clarke et al., 2014; Goode et al., 2014).

The emergency department is a focal point of contact for many vulnerable individuals and those of sub-groups who may require specific support, such as young people in out-of-home care, with suicidal ideation (Cronholm et al., 2010), or people from certain racial and ethnic minorities (Wells et al., 2013). Mental health presentations to ED are often complex, in conjunction with other factors and may include situational crises such as homelessness and substance misuse (Funn \& Woodruff, 2011), and therefore require deliberate psychosocial attention.

Reviewed articles noted that in the ED setting, social workers are required to assist people with depression (Wells et al., 2013), those with acute anxiety or panic attacks (Katerndahl, 1996), older persons with chronic mental health concerns (Joubert et al., 2013; Thienhaus \& Piasecki, 2004) and those with behavioural problems (Thienhaus \& Piasecki, 2004). Reviewed studies also noted the growing need for crisis intervention, as police and other officers divert mentally ill people in crisis away from the criminal justice system to the 
hospital emergency system (Tyuse, 2012). This further underscores the need for enhanced psychosocial support by social workers in the ED setting (Tyuse, 2012).

The current literature review identified a number of social work related skills which are very important in assisting people with mental health conditions in the ED setting. These include specialised intervention skills in responding to those with mental health needs (Clarke et al., 2014; Goode et al., 2014; Tyuse, 2012), problem solving abilities (Alonzo et al., 2013) and more general case management skills (Griswold et al., 2008). Social workers in this setting have a unique role and capacity to listen, empathise and give advice (Wells et al., 2013). In particular, their skills include crisis intervention and debriefing. When applied correctly in the early stages following a traumatic event, it can enhance the recovery process and reduce negative long term psychological impacts (Bell, 1995). Social workers are also specially trained to identify potential crises in the context of psychosocial stressors, and assist to de-escalate, as well as link patients with community organisations which can support the individual more appropriately (Moore et al., 2012). As noted above, the ability to identify and link patients with appropriate community support, contributes to the prevention of unnecessary hospital admissions and re-presentations (Auerbach \& Mason, 2010; Cleak \& Turczynski, 2014). Conversely, social worker involvement in this setting may also maximise non-hospital referrals (Mason \& Auerbach, 2009), especially when backed up by community mental health support (Putman, 1998).

While social workers can play a vital immediate role in the ED setting for people with mental health issues, a key advantage is that the role extends beyond the ED crisis, to inform discharge planning, therapeutic interventions, follow-up, community support and referrals, as well as advocacy (Alonzo et al., 2013; Auerbach \& Mason, 2010; Clarke et al., 2014; Lindsey et al., 2010; Mason \& Auerbach, 2009; Spurrell, Hatfield, \& Perry, 2003; Thienhaus \& Piasecki, 2004). The social worker is uniquely positioned to look outside of the medical model to provide understanding and empathy for the patient's lived situation (Wells et al., 2013), with an emphasis on their social context community linkages (Lindsey et al., 2010), thereby potentially averting future ED admissions.

\subsection{Key Practice Area - Suicide Risk and Crisis}

As reflected above, a core theme across the reviewed literature is that people in psychological distress often present at ED in crisis (Baraff et al., 2006). Emergency departments are a focal point through which to reach some people with depression and anxiety (Funn \& Woodruff, 2011), and those of some ethnic communities who experience distress (Wells et al., 2013). Other key groups noted in the review include elderly people in psychological crises (Joubert et al., 2013), people experiencing panic attacks or acute anxiety (Katerndahl, 1996) adolescents with depression (Cronholm et al., 2010; Funn \& Woodruff, 2011), drug users at risk of overdose (Jones et al., 2002), and young people who may have suicidal ideation or self-inflicted injuries (Rhodes et al., 2012; Rhodes et al., 2013). Indeed for many people in psychological crisis, the ED may be the key point of contact, and social work input in that setting is vital. Further, the emergency department is a crucial site for engaging with such patients and their families (Baraff et al., 2006; Jones et al., 2002), to facilitate the management of psychosocial concerns and to mitigate adverse outcomes. 
Unfortunately, despite the prevalence of people who present to ED in psychological distress, the issue of under-diagnosis of these issues is a major concern (Wells et al., 2013). Under-diagnosis of depression and other conditions in ED, especially for people from racial and ethnic minorities, is evident in ED systems, and underscores the importance of enhanced social work input (Wells et al., 2013).

Beyond the follow-up and outreach strategies highlighted in the previous section, social work led interventions with people in psychological crisis and at risk of suicide, was strongly advocated in the reviewed literature (Baraff et al., 2006; Clarke et al., 2014; Joubert, Petrakis, \& Cementon, 2012; Petrakis \& Joubert, 2013). In particular, in the case of suicide risk, the specific supports offered by social workers are beneficial (Lizardi \& Stanley, 2010). For children at risk of suicide, social work support which is sensitive to family difficulties, to social context, and which encompasses sensitivity to repetition of such behaviours, is required (Rhodes et al., 2013). While engaging with such patients and providing psychosocial interventions are very difficult, without adequate psychosocial follow-up, they are likely to make further attempts post-discharge (Lizardi \& Stanley, 2010).

In this light, reviewed articles emphasised that social workers in ED should have comprehensive training and skills in psychological screening, problem solving (Alonzo et al., 2013) and traumatic event debriefing (Bell, 1995). Particular articles emphasised the need for, and benefits of, screening for depression and related issues (Cronholm et al., 2010), for older persons mental health concerns (Joubert et al., 2013), and for suicidality (Lizardi \& Stanley, 2010).

\subsection{Key Practice Area - Chronic Disease}

Beyond crisis situations, some reviewed articles emphasised that social workers in ED settings have a key role in assisting people in the area of chronic disease (Hill et al., 2013). While many aspects of chronic disease are managed in primary health care settings, those with higher complexity (including interactions between chronic disease and depression) often present at ED for care (Spurrell et al., 2003). In this context people require support to deal with worsening symptoms, and to enhance their emotional, functional and physical coping, which are core social work skill areas (Hill et al., 2013). As with other patient groups in ED, social workers can make substantial impact on the welfare of those with chronic disease by providing health promotion and preventive health assistance at discharge (Hill et al., 2013).

The review noted the potential benefit of social work involvement in chronic care plans (Hill et al., 2013). As a result, there is a need for enhanced assessment and care planning tools to enable social workers to have greater input and impact with these patients (Hill et al., 2013). Social workers provide support to assist patients to identify and articulate the psychosocial impact of health concerns and progress this conversation to problem identification, goal setting, and then to a sense of increased confidence and control in managing their health needs. Social workers also identify and support patient engagement with a range of specialist services able to best meet gaps in health care and other psychosocial needs. Social workers undertake a central role in supporting continuity in service response for frequent ED re-presenters by developing patient centred service plans that identify established responses to health and psychosocial needs, and the roles of stakeholders in patient care. 


\subsection{Priority Focus Area - Social Work Screening and Assessment in ED}

The reviewed literature also highlighted that social work related screening and assessment is an important contribution in the ED setting (Cleak \& Turczynski, 2014). Reviewed articles noted the benefit of social work screening and assessment for suicidality and self-harm (Lizardi \& Stanley, 2010) mental health status, emotional and behavioural concerns (Auerbach \& Mason, 2010), alcohol dependence, consumption and related concerns (Kenna et al., 2005), chronic care, and (Hill et al., 2013) broader psychosocial and quality of life issues (Petrakis \& Joubert, 2013).

Importantly it was evident from the literature that any tools or methods for social work screening should be evidence based (Auerbach \& Mason, 2010), and appropriately validated (Petrakis \& Joubert, 2013) to meaningfully guide and inform social work interventions in the context of the multi-disciplinary team (Auerbach \& Mason, 2010). Assessments should be contextually sensitive, acknowledging the types of presentations and referrals, with relevance to other team members, and potentially gauge expected outcomes and patient satisfaction (Petrakis \& Joubert, 2013). Enhancement of these assessments and screening tools is seen as a crucial means of establishing the role and contribution of social work in the ED setting.

\subsection{Priority Focus Area - A Social Work Model That is Relevant to ED}

Given the breadth of potential avenues of social worker involvement in ED, it would appear that a coherent model of practice may also be beneficial to informing greater social work engagement in this setting. While proposing a theory is beyond the scope of the current study, some relevant points may be noted for a model that informs social work practice in the ED setting.

Such a model would accommodate a focus on patient outcomes (Moore et al., 2012), a commitment to a holistic approach (Petrakis \& Joubert, 2013), and recognition of the impact of complexity (Joubert et al., 2013; Messinger, 2011) on all aspects of patient reality and service context. It would emphasise the need to balance the individual, patient-centred, psychosocial approach (Goode et al., 2014; Petrakis \& Joubert, 2013) with the family and social context (Messinger, 2011), as well as system and structural context realities (Moore et al., 2012; Wand et al., 2011). Two reviewed articles posit that a realist conceptual framework, focusing on the interplay between context, mechanisms and outcomes may fit these requirements (Wand et al., 2010, 2011). The realist approach is consistent with social work in recognising that it is not necessarily the programmes or interventions that work, but rather people co-operating and choosing to make them work (Wand et al., 2010, 2011).

While the findings of this review provide useful insights into this topic, a number of limitations should also be noted. First, unfortunately there were few conclusive or experimental studies identified in the review. While it was possible to identify some higher quality and relevance studies from the selected articles using the agreed criteria (Appendix 1), on the whole the reviewed studies were more opinion and perspective pieces, but included descriptive, observational, qualitative and retrospective studies. In general this area lacks strong quantitative and controlled studies as well as rigorous comparisons or critical analysis of the role of social work in ED. There is clearly a need to critically analyse and appraise the potential role of social workers in these contexts. Such a critical analysis could be based on 
the key concepts identified in this review.

Second, while this review has identified useful concepts, the findings are by no means exhaustive. For example, database searches were constrained by the practical reality of juggling research in the context of clinical practice. Despite these limitations, the current review serves as a good foundation for future research

\section{Conclusion}

In this project, social workers in a clinical setting identified an issue of concern in their current practice, refined a research question, conducted a clinically relevant scoping review, critically appraised research, and drew important conclusions from their appraisal. The resulting review also identified a number of key dimensions to inform practice and planning for expanded social work roles in ED. It has identified three key practice areas of social work involvement in emergency departments, namely: mental health, suicide risk and crisis, and chronic disease. It has also identified two priority focus areas from the literature, namely: social work screening and assessment in ED, and developing a social work model that is relevant to ED. The review concludes that social workers have an integral role in the emergency department team, and specifically in assisting patients with complex psycho-social and emotional concerns, vulnerable patients, the elderly, adolescents, and those with mental health concerns (Cronholm et al., 2010; Joubert et al., 2012). In documenting this breadth of input, the current review also highlights the need for skilled and experienced staff in ED (Clarke et al., 2014). Clearly, the role of social workers in ED settings is complex and emotionally taxing, so adequate training, support, and professional self-care are very important (Doyle, 2000). Beyond standard social work competencies, and psychosocial intervention skills, the review noted the need for specific skills in social work assessment (Baraff et al., 2006) and in dealing with critical incidents (Tyuse, 2012). The strong relational dimension of the work underscores the need for strong communication skills, as well as skills for establishing, maintaining, and strengthening relationships (Kelly, 2005).

Patients are utilizing hospital emergency departments at increasing rates for both urgent and non-urgent conditions; the costs of these services are high. Social workers can play a vital role in providing comprehensive care to patients in this setting (Moore et al., 2012). Indeed from the literature reviewed, timely access to social work in the ED, creates scope for improved patient services, more effective discharges and critical psychosocial interventions when they are most required (Moore et al., 2012).

In summary, this scoping review has highlighted a clear lack of quality research in the area of direct social work practice in the emergency department. Despite this, it had shone a light on the unique contribution that social workers can apply to a variety of complex presentation in the emergency setting. Additionally it shows the potential scope of their interventions and contribution to supporting patients and reducing hospital admissions. The key themes included three key practice areas where social workers provide vital services in ED, and which should be the focus of professional expansion. In identifying the two priority focus areas of screening/assessment and a social work model, the current review has highlighted priorities for professional expansion. Moving forward, further research and development of an appropriate model based on these themes could provide a consistent, structured approach to care and enhance the role of social work within emergency departments world wide. 


\section{References}

Alonzo, D., Stanley, B., Cournos, F., \& Goldfinger, S. M. (2013). A novel intervention for treatment of suicidal individuals. Psychiatric Services, 64(5), 494-494. https://doi.org/10.1176/appi.ps.640105

Anderson, S., Allen, P., Peckham, S., \& Goodwin, N. (2008). Asking the right questions: scoping studies in the commissioning of research on the organisation and delivery of health services. Health Res Policy Syst, 6(7), 1-12. https://doi.org/10.1186/1478-4505-6-7

Arksey, H., \& O'Malley, L. (2005). Scoping studies: towards a methodological framework. International journal of social research methodology, 8(1), 19-32. https://doi.org/10.1080/1364557032000119616

Auerbach, C., \& Mason, S. E. (2010). The value of the presence of social work in emergency departments. Social Work in Health Care, 49(4), 314-326. https://doi.org/10.1080/00981380903426772

Baraff, L. J., Janowicz, N., \& Asarnow, J. R. (2006). Survey of California emergency departments about practices for management of suicidal patients and resources available for their care. Annals of Emergency Medicine, 48(4), 452. https://doi.org/10.1016/j.annemergmed.2006.06.026

Bell, J. L. (1995). Traumatic Event Debriefing: Service Delivery Designs and the Role of Social Work. Social Work, 40(1), 36-43. Retrieved from http://search.ebscohost.com/login.aspx?direct=true\&AuthType=ip,athens\&db=sih\&AN=951 0161945\&site $=$ ehost-live

Clarke, D., Usick, R., Sanderson, A., Giles-Smith, L., \& Baker, J. (2014). Emergency department staff attitudes towards mental health consumers: A literature review and thematic content analysis. International Journal of Mental Health Nursing, 23(3), 273-284. https://doi.org/10.1111/inm.12040

Cleak, H. M., \& Turczynski, M. (2014). Hospital social work in Australia: Emerging trends or more of the same? Social Work in Health Care, 53(3), 199-213. https://doi.org/10.1080/00981389.2013.873516

Cronholm, P. F., Barg, F. K., Pailler, M. E., Wintersteen, M. B., Diamond, G. S., \& Fein, J. A. (2010). Adolescent depression: views of health care providers in a pediatric emergency department. Pediatric Emergency Care, 26(2), 111-117. https://doi.org/10.1097/PEC.0b013e3181ce2f85

Daudt, H. M., Van Mossel, C., \& Scott, S. J. (2013). Enhancing the scoping study methodology: a large, inter-professional team's experience with Arksey and O'Malley's framework. BMC Medical Research Methodology, 13(1), 48. https://doi.org/10.1186/1471-2288-13-48

Doyle, L. (2000). Surviving emergency social work: experience of an Australian Accident \& Emergency Department. Accident and emergency nursing, 8(3), 165-169. https://doi.org/10.1054/aaen.2000.0138

Fitzgerald, K., Wooler, S., Petrovic, D., Crickmore, J., Fortnum, K., Hegarty, L., ... Kuipers, P. (2017). Barriers to engagement in acute and post-acute sexual assault response services: A 
practice-based scoping review. International journal of emergency mental health and human resilience, 19(2). https://doi.org/10.4172/1522-4821.1000361

Funn, J., \& Woodruff, S. I. (2011). Prevalence and Sociodemographic Correlates of Mental Health Problems Among Emergency Department Patients With High-Risk and Dependent Alcohol Use Patterns. Journal of Dual Diagnosis, 7(1/2), 14-25. https://doi.org/10.1080/15504263.2011.569192

Goode, D., Melby, V., \& Ryan, A. (2014). Management of patients with mental health needs: Debbie Goode and colleagues assess whether staff are prepared to offer person-centred care to all people who present to emergency departments. Emergency Nurse, 22(5), 32-37. https://doi.org/10.7748/en.22.5.32.e1337

Griswold, K. S., Zayas, L. E., Pastore, P. A., Smith, S. J., Wagner, C. M., \& Servoss, T. J. (2008). Primary care after psychiatric crisis: a qualitative analysis. The Annals of Family Medicine, 6(1), 38-43. https://doi.org/10.1370/afm.760

Hill, N., Joubert, L., \& Epstein, I. (2013). Encouraging Self-Management in Chronically Ill Patients With Co-Morbid Symptoms of Depression and Anxiety: An Emergency Department Study and Response. Social Work in Health Care, 52(2-3), 207-221. https://doi.org/10.1080/00981389.2012.737900

Jones, R., Gruer, L., Gilchrist, G., Seymour, A., Black, M., \& Oliver, J. (2002). Recent contact with health and social services by drug misusers in Glasgow who died of a fatal $\begin{array}{llll}\text { overdose in } \quad 1999 . & \text { Addiction, } & \text { 97(12), }\end{array}$ https://doi.org/10.1046/j.1360-0443.2002.00244.x

Joubert, L., Lee, J., McKeever, U., \& Holland, L. (2013). Caring for Depressed Elderly in the Emergency Department: Establishing Links Between Sub-Acute, Primary, and Community Care. Social Work in Health Care, 52(2/3), 222-238. https://doi.org/10.1080/00981389.2012.737896

Joubert, L., Petrakis, M., \& Cementon, E. (2012). Suicide attempt presentations at the emergency department: outcomes from a pilot study examining precipitating factors in deliberate self-harm and issues in primary care physician management. Social Work in Health Care, 51(1), 66-76. https://doi.org/10.1080/00981389.2011.622673

Katerndahl, D. A. (1996). Panic attacks and panic disorder. Journal of family practice, 43(3), 275-283.

Kelly, A. E. (2005). Relationships in emergency care: communication and impact. Advanced Emergency Nursing Journal, 27(3), 192-197.

Kenna, G. A., Longabaugh, R., Gogineni, A., Woolard, R. H., Nirenberg, T. D., Becker, B., ... Karolczuk, K. (2005). Can the short index of problems (SIP) be improved? Validity and reliability of the three-month SIP in an emergency department sample. Journal of studies on alcohol, 66(3), 433-437. https://doi.org/10.15288/jsa.2005.66.433

Levac, D., Colquhoun, H., \& O'Brien, K. K. (2010). Scoping studies: advancing the methodology. Implement Sci, 5(1), 1-9. https://doi.org/10.1186/1748-5908-5-69

Lindsey, M. A., Joe, S., Muroff, J., \& Ford, B. E. (2010). Social and clinical factors associated with psychiatric emergency service use and civil commitment among 
African-American youth. General Hospital Psychiatry, 32(3), 300-309. https://doi.org/10.1016/j.genhosppsych.2010.01.007

Lizardi, D., \& Stanley, B. (2010). Treatment engagement: a neglected aspect in the psychiatric care of suicidal patients. Psychiatric Services. https://doi.org/10.1176/ps.2010.61.12.1183

Lubomirsky, B., Wang, X., Xie, H., Smirnoff, J. B., Biehn, T. L., Contractor, A. A., ... Liberzon, I. (2014). Preliminary study on the relationship between visitation in the emergency department and posttraumatic mental health. Social Work in Mental Health, 12(1), 69-80. https://doi.org/10.1080/15332985.2013.841611

Mason, S. E., \& Auerbach, C. (2009). Factors related to admissions to a psychiatry unit from a medical emergency room: The role of social work. Social Work in Mental Health, 7(5), 429-441. https://doi.org/10.1080/15332980802545046

McClennen, J., Keys, A. M., \& Day, M. (2016). Social work and family violence: Theories, assessment, and intervention: Springer Publishing Company. https://doi.org/10.1891/9780826133496

McCormack, R. P., Williams, A. R., Goldfrank, L. R., Caplan, A. L., Ross, S., \& Rotrosen, J. (2013). Commitment to assessment and treatment: comprehensive care for patients gravely disabled by alcohol use disorders. The Lancet, 382(9896), 995-997. https://doi.org/10.1016/S0140-6736(12)62206-5

McMichael, A. (2000). Professional identity and continuing education: A study of social workers in hospital settings. Social Work Education, 19(2), 175-183. https://doi.org/10.1080/02615470050003557

Meng, X., Muggli, T., Baetz, M., \& D'Arcy, C. (2017). Disordered lives: Life circumstances and clinical characteristics of very frequent users of emergency departments for primary mental health complaints. Psychiatry Res, 252, 9-15. https://doi.org/10.1016/j.psychres.2017.02.044

Messinger, S. D. (2011). Cooperation and contention in psychiatric work. Transcultural Psychiatry, 48(3), 284-298. https://doi.org/10.1177/1363461511402867

Moore, M., Ekman, E., \& Shumway, M. (2012). Understanding the critical role of social work in safety net medical settings: framework for research and practice in the emergency department. Social Work in Health Care, 51(2), 140-148. https://doi.org/10.1080/00981389.2011.610872

Moriarty, J., \& Manthorpe, J. (2016). The Effectiveness of Social Work with Adults. A Systematic Scoping Review.

Ogilvie, D., Fayter, D., Petticrew, M., Sowden, A., Thomas, S., Whitehead, M., \& Worthy, G. (2008). The harvest plot: a method for synthesising evidence about the differential effects of interventions. BMC Med Res Methodol, 8, 8. https://doi.org/10.1186/1471-2288-8-8

Petrakis, M., \& Joubert, L. (2013). A social work contribution to suicide prevention through assertive brief psychotherapy and community linkage: Use of the Manchester Short Assessment of Quality of Life (MANSA). Social Work in Health Care, 52(2-3), 239-257. https://doi.org/10.1080/00981389.2012.737903 
Pines, J. M., Asplin, B. R., Kaji, A. H., Lowe, R. A., Magid, D. J., Raven, M., ... Yealy, D. M. (2011). Frequent users of emergency department services: gaps in knowledge and a proposed research agenda. Acad Emerg Med, 18(6), e64-69. https://doi.org/10.1111/j.1553-2712.2011.01086.x

Putman, S. (1998). Extended hours community mental health nursing service. Accident and emergency nursing, 6(4), 192-196. https://doi.org/10.1016/S0965-2302(98)90078-9

Räsänen, J.-M. (2012). Producing norm talk of fact-based case recording in interviews with emergency social workers. Qualitative Social Work, 11(1), 6-22. https://doi.org/10.1177/1473325011400482

Rhodes, A. E., Boyle, M. H., Bethell, J., Wekerle, C., Goodman, D., Tonmyr, L., ... Manion, I. (2012). Child maltreatment and onset of emergency department presentations for suicide-related behaviors. Child Abuse \& Neglect, 36(6), 542-551. https://doi.org/10.1016/j.chiabu.2012.04.006

Rhodes, A. E., Boyle, M. H., Bethell, J., Wekerle, C., Tonmyr, L., Goodman, D., ... Manion, I. (2013). Child maltreatment and repeat presentations to the emergency department for suicide-related behaviors. Child Abuse \& Neglect, 37(2), 139-149. https://doi.org/10.1016/j.chiabu.2012.07.009

Rozas, L. W., \& Klein, W. C. (2010). The Value and Purpose of the Traditional Qualitative Literature Review. Journal of Evidence-Based Social Work, 7(5), 387-399. https://doi.org/10.1080/15433710903344116

Ryan, J., Clemmett, S., \& Snelson, A. (1997). Role of a psychiatric liaison nurse in an A \& E department. Accident and emergency nursing, 5(3), 152-155. https://doi.org/10.1016/S0965-2302(97)90010-2

Spurrell, M., Hatfield, B., \& Perry, A. (2003). Characteristics of patients presenting for emergency psychiatric assessment at an English hospital. Psychiatric Services, 54(2), 240-245. https://doi.org/10.1176/appi.ps.54.2.240

Thienhaus, O. J., \& Piasecki, M. P. (2004). Emergency psychiatry: assessment of geriatric patients in the psychiatric emergency service. Psychiatric Services. https://doi.org/10.1176/appi.ps.55.6.639

Tyuse, S. W. (2012). A Crisis Intervention Team Program: Four-Year Outcomes. Social Work in Mental Health, 10(6), 464-477. https://doi.org/10.1080/15332985.2012.708017

Wand, T., White, K., \& Patching, J. (2010). Applying a realist (ic) framework to the evaluation of a new model of emergency department based mental health nursing practice. Nursing inquiry, 17(3), 231-239. https://doi.org/10.1111/j.1440-1800.2008.00407.x

Wand, T., White, K., \& Patching, J. (2011). Realistic evaluation of an emergency department-based mental health nurse practitioner outpatient service in Australia. Nursing \& health sciences, 13(2), 199-206. https://doi.org/10.1111/j.1442-2018.2011.00601.x

Wells, A., Lagomasino, I. T., Palinkas, L. A., Green, J. M., \& Gonzalez, D. (2013). Barriers to depression treatment among low-income, Latino emergency department patients. $\begin{array}{llll}\text { Community Mental Health } & \text { J9urnal, } & \text { 412-418. }\end{array}$ https://doi.org/10.1007/s10597-012-9547-5 


\section{Quality, Relevance and Summary of Findings}

\begin{tabular}{|l|l|l|}
\hline Authors \& Year & & \\
\hline Title & \\
\hline Journal / Source & \\
\hline
\end{tabular}

\section{Quality:}

1. AIMS \& PROBLEM How clear are the aims of the research?

\begin{tabular}{l|l|l|l|l|l|}
\hline $\mathbf{1} \quad$ Not clear & $\mathbf{2}$ & $\mathbf{3}$ Somewhat & $\mathbf{4}$ & $\mathbf{5}$ & Very clear \\
\hline Consider & \\
- Is the reason for the research clear? Is there a good description of the problem? \\
• Have previous research findings and/or theories been considered?
\end{tabular}

2. METHODS How well does the paper set out the methods used in the study?

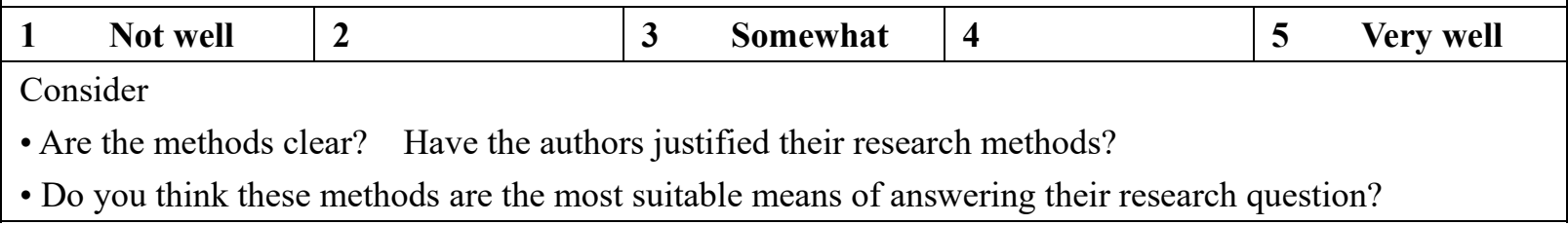

\section{RESULTS \& DISCUSSION How well are the results presented?}

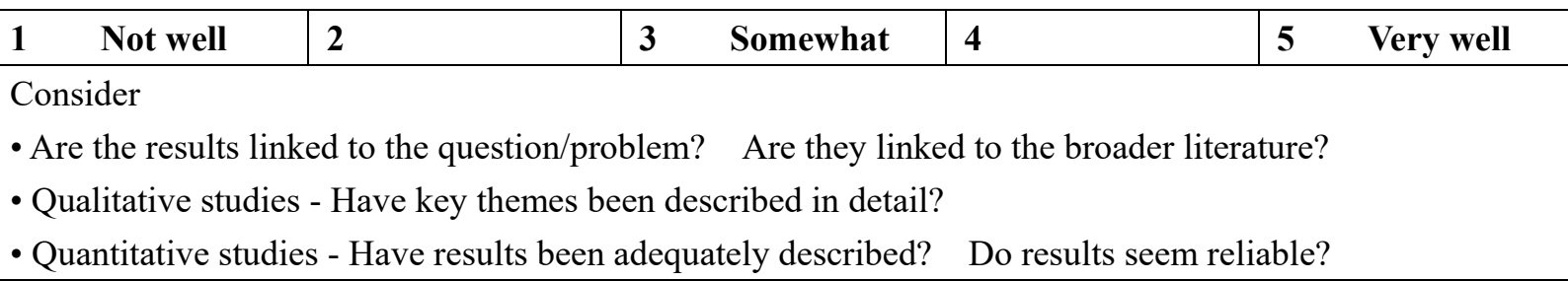

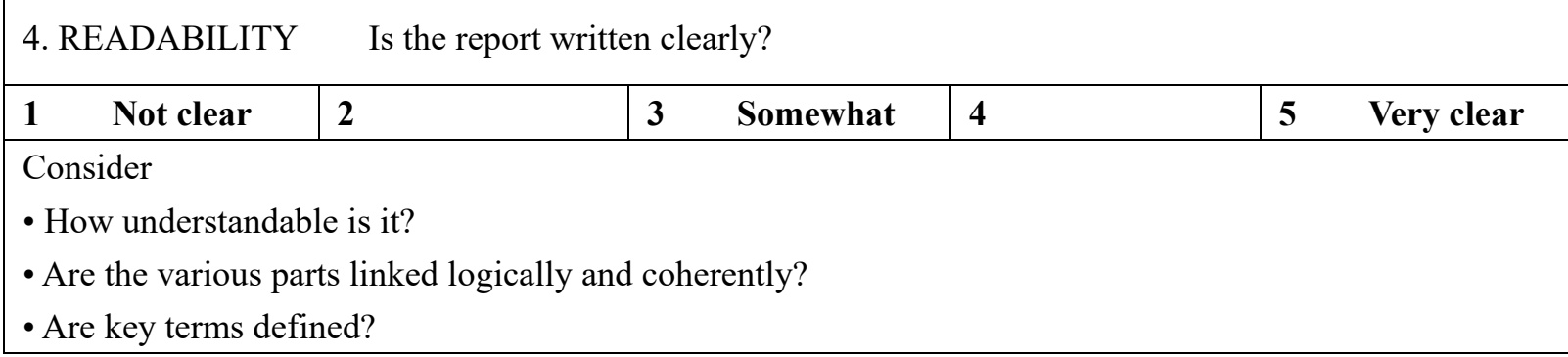


5. IMPLICATIONS Does the report draw clear links to practice, policy or further research?

\begin{tabular}{|c|c|c|c|c|c|c|c|}
\hline 1 & Not really & 2 & 3 & Somewhat & 4 & 5 & Very much \\
\hline \multicolumn{8}{|c|}{ Consider } \\
\hline
\end{tabular}

\section{TALLY: Quality Score:}

\section{Relevance:}

6. CONTENT How relevant is the paper to your review question?

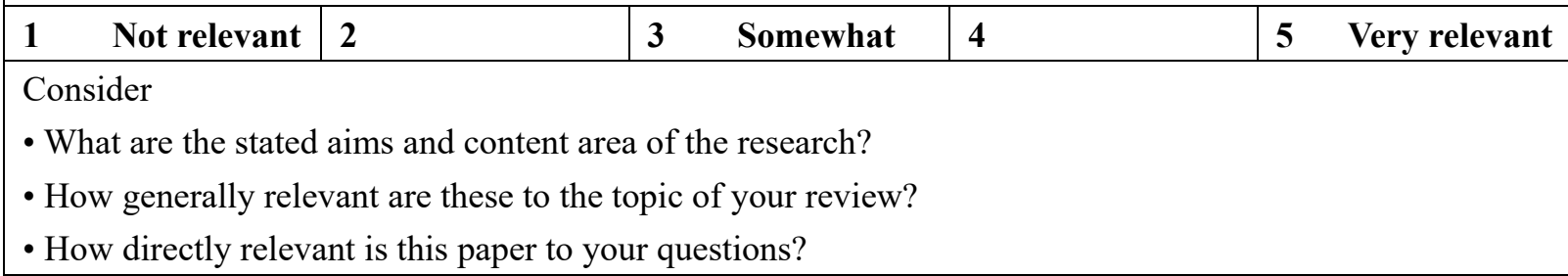

7. FOCUS How focused is the paper on your professional area (e.g Social Work, Child Therapy)

\begin{tabular}{|c|c|c|c|c|c|c|c|}
\hline 1 & Not really & 2 & 3 & Somewhat & 4 & 5 & Very much \\
\hline \multicolumn{8}{|c|}{$\begin{array}{l}\text { Consider } \\
\text { - Is there a clear link between the profession / discipline focus of the paper and that of your team and your } \\
\text { question? }\end{array}$} \\
\hline
\end{tabular}

\section{CONTEXT Is the context of the research comparable with your practice context?}

\begin{tabular}{|l|l|l|l|ll|}
\hline $\mathbf{1} \quad$ Not really & $\mathbf{2}$ & $\mathbf{3}$ Somewhat & $\mathbf{4}$ & $\mathbf{5}$ & Very much \\
\hline $\begin{array}{l}\text { Consider } \\
\bullet \text { How similar are things like client demographics, service model, resource environment, etc.? }\end{array}$ \\
\hline
\end{tabular}

9. UTILITY How useable is the information provided in the paper for your practice?

\begin{tabular}{|c|c|c|c|c|c|c|}
\hline Not useable & 2 & 3 & Somewhat & 4 & $\begin{array}{l}5 \\
\text { useable }\end{array}$ & Very \\
\hline \multicolumn{7}{|l|}{ Consider } \\
\hline \multicolumn{7}{|c|}{ - Is the research conducted and presented in such a way that it is usable for your practice. } \\
\hline \multicolumn{7}{|c|}{ - Utility may be practical as well as theoretical (helping you develop useful ideas). } \\
\hline
\end{tabular}


TALLY: Relevance Score:

Summary of findings /key points that relate to the review question: 
Appendix 2. Reviewed article characteristics

\begin{tabular}{|c|c|c|c|c|c|}
\hline $\begin{array}{l}\text { Author and } \\
\text { Year }\end{array}$ & Country & Method/Study Design & $\begin{array}{l}\text { Assessment Methods } \\
\text { Used }\end{array}$ & Perspective & Qual \& Rel* \\
\hline $\begin{array}{l}\text { Alonzo et al } \\
(2013)\end{array}$ & USA & $\begin{array}{l}\text { Qualitative. Description of interview } \\
\text { protocol }\end{array}$ & $\begin{array}{l}\text { Problem-Solving and } \\
\text { Comprehensive } \\
\text { Contact Intervention }\end{array}$ & $\begin{array}{l}\text { Mental Health/ } \\
\text { Psychiatry }\end{array}$ & Adequate \\
\hline $\begin{array}{l}\text { Auerbach et } \\
\text { al (2010) }\end{array}$ & USA & $\begin{array}{l}\text { Qualitative \& Quantitative - } \\
\text { Retrospective data analysis of Social } \\
\text { Work intervention }\end{array}$ & N/A & Social Work & Higher \\
\hline $\begin{array}{l}\text { Baraff et al } \\
(2006)\end{array}$ & USA & $\begin{array}{l}\text { Quantitative - Retrospective data analysis } \\
\text { of suicidal patients }\end{array}$ & N/A & $\begin{array}{l}\text { Mental Health/ } \\
\text { Psychiatry }\end{array}$ & Intermediate \\
\hline Bell (1995) & USA & $\begin{array}{l}\text { Literature Review and Theoretical } \\
\text { Analysis }\end{array}$ & N/A & Social Work & Adequate \\
\hline $\begin{array}{l}\text { Clarke et al } \\
(2014)\end{array}$ & Canada/UK & $\begin{array}{l}\text { Literature Review and Theoretical } \\
\text { Analysis }\end{array}$ & N/A & Nursing & Intermediate \\
\hline $\begin{array}{l}\text { Cleak et al } \\
(2014\end{array}$ & Australia & $\begin{array}{l}\text { Literature Review and Theoretical } \\
\text { Analysis }\end{array}$ & $\mathrm{N} / \mathrm{A}$ & Social Work & Adequate \\
\hline $\begin{array}{l}\text { Cronholm et } \\
\text { al (2010) }\end{array}$ & USA & Qualitative - Interview of Health workers & N/A & Public / Pop'n Hth. & Intermediate \\
\hline Doyle (2000) & Australia & Experiential Narrative & $\mathrm{N} / \mathrm{A}$ & Social Work & Adequate \\
\hline $\begin{array}{l}\text { Funn et al } \\
(2011)\end{array}$ & USA & Quantitative - Retrospective data analysis & N/A & $\begin{array}{l}\text { Social } \\
\text { Work/Medical }\end{array}$ & Intermediate \\
\hline $\begin{array}{l}\text { Goode et al } \\
(2014)\end{array}$ & UK & Qualitative - Interview of Health workers & N/A & Nursing & Intermediate \\
\hline $\begin{array}{l}\text { Griswold et } \\
\text { al (2008) }\end{array}$ & USA & $\begin{array}{l}\text { Qualitative \& Quantitative - } \\
\text { Semi-structured interview }\end{array}$ & $\begin{array}{l}\text { Short Form Healthy } \\
\text { Survey (SF-36) }\end{array}$ & $\begin{array}{l}\text { Mental Health/ } \\
\text { Psychiatry }\end{array}$ & Intermediate \\
\hline $\begin{array}{l}\text { Hill et al } \\
(2013)\end{array}$ & $\begin{array}{l}\text { Australia/ } \\
\text { USA }\end{array}$ & $\begin{array}{l}\text { Quantitative - Retrospective data analysis } \\
\text { of }\end{array}$ & N/A & Social Work & Intermediate \\
\hline Holland 2010 & USA & $\begin{array}{l}\text { Qualitative \& Quantitative - } \\
\text { Retrospective data analysis }\end{array}$ & N/A & Social Work & Intermediate \\
\hline $\begin{array}{l}\text { Jones et al } \\
(2002)\end{array}$ & UK & $\begin{array}{l}\text { Qualitative \& Quantitative - } \\
\text { Retrospective data analysis }\end{array}$ & $\mathrm{N} / \mathrm{A}$ & Public / Pop'n Hth. & Adequate \\
\hline $\begin{array}{l}\text { Joubert et al } \\
(2012)\end{array}$ & Australia & $\begin{array}{l}\text { Quantitative \& Quantitative - } \\
\text { Retrospective data analysis \& semi } \\
\text { structured interviews }\end{array}$ & $\begin{array}{l}\text { Beck Depression } \\
\text { Inventory }\end{array}$ & Social Work & Higher \\
\hline $\begin{array}{l}\text { Joubert et al } \\
(2013)\end{array}$ & Australia & $\begin{array}{l}\text { Quantitative \&Quantitative - } \\
\text { Retrospective data analysis and semi } \\
\text { structured interviews }\end{array}$ & $\begin{array}{l}\text { Geriatric Depression } \\
\text { Screening Tool, PIE, } \\
\text { MANSA, MOS, } \\
\text { Satisfaction. }\end{array}$ & Social Work & Intermediate \\
\hline $\begin{array}{l}\text { Katerndahl } \\
(1996)\end{array}$ & USA & Quantitative - Retrospective data analysis & DSM-IV & Medical & Adequate \\
\hline Kelly (2005) & USA & $\begin{array}{l}\text { Literature Review and Theoretical } \\
\text { Analysis }\end{array}$ & $\mathrm{N} / \mathrm{A}$ & Nursing & Adequate \\
\hline
\end{tabular}




\begin{tabular}{|c|c|c|c|c|c|}
\hline $\begin{array}{l}\text { Kenna et al } \\
(2005)\end{array}$ & USA & $\begin{array}{l}\text { Quantitative \&Quantitative - } \\
\text { Retrospective data analysis. Semi } \\
\text { structured interviews }\end{array}$ & $\begin{array}{l}\text { Short Index of } \\
\text { Problems, Alcohol } \\
\text { Use Disorders } \\
\text { Identification Test }\end{array}$ & Medical & Adequate \\
\hline $\begin{array}{l}\text { Lindsey et al } \\
(2010)\end{array}$ & USA & Quantitative - Retrospective data analysis & DSM-IV & Social Work & Intermediate \\
\hline $\begin{array}{l}\text { Lizardi et al } \\
(2010)\end{array}$ & USA & $\begin{array}{l}\text { Literature Review and Theoretical } \\
\text { Analysis }\end{array}$ & N/A & $\begin{array}{l}\text { Mental Health/ } \\
\text { Psychiatry }\end{array}$ & Intermediate \\
\hline $\begin{array}{l}\text { Lubomirsky } \\
\text { et al (2014) }\end{array}$ & USA & $\begin{array}{l}\text { Quantitative \& Quantitative - } \\
\text { Retrospective data analysis. Semi } \\
\text { structured interviews }\end{array}$ & $\begin{array}{l}\text { Abbreviated Injury } \\
\text { Scale, PTSD } \\
\text { Checklist, Depression } \\
\text { Scale, } \\
\text { Anxiety Inventory }\end{array}$ & $\begin{array}{l}\text { Mental Health/ } \\
\text { Psychiatry }\end{array}$ & Adequate \\
\hline $\begin{array}{l}\text { Mason et al } \\
(2009)\end{array}$ & USA & Quantitative- Retrospective data analysis & N/A & Social Work & Higher \\
\hline $\begin{array}{l}\text { McCormack } \\
\text { et al (2013) }\end{array}$ & USA & $\begin{array}{l}\text { Qualitative \& Quantitative - } \\
\text { Retrospective data analysis }\end{array}$ & N/A & Public / Pop'n Hth. & Higher \\
\hline $\begin{array}{l}\text { Messinger } \\
(2011)\end{array}$ & USA & Qualitative - Review of practices & $\mathrm{N} / \mathrm{A}$ & Public / Pop'n Hth. & Adequate \\
\hline $\begin{array}{l}\text { Moore et al } \\
(2012)\end{array}$ & USA & $\begin{array}{l}\text { Literature Review and Theoretical } \\
\text { Analysis }\end{array}$ & N/A & Social Work & Adequate \\
\hline Olfson 2005 & USA & Quantitative- Retrospective data analysis & N/A & $\begin{array}{l}\text { Social Work/ } \\
\text { Psychiatry/ Medical }\end{array}$ & Intermediate \\
\hline $\begin{array}{l}\text { Petrakis et al } \\
(2013)\end{array}$ & Australia & $\begin{array}{l}\text { Qualitative \& Quantitative - } \\
\text { Retrospective data analysis }\end{array}$ & $\begin{array}{l}\text { Manchester Short } \\
\text { Assessment of Quality } \\
\text { of Life (MANSA) }\end{array}$ & Social Work & Higher \\
\hline $\begin{array}{l}\text { Rhodes et al } \\
(2012)\end{array}$ & Canada & $\begin{array}{l}\text { Quantitative- Retrospective data analysis } \\
\text { of }\end{array}$ & $\begin{array}{l}\text { ED presentations, } \\
\text { demographic social } \\
\text { and clinical variables }\end{array}$ & Public / Pop'n Hth. & Intermediate \\
\hline $\begin{array}{l}\text { Rhodes et al } \\
(2013)\end{array}$ & Canada & $\begin{array}{l}\text { Quantitative- Retrospective data analysis } \\
\text { of }\end{array}$ & $\begin{array}{l}\text { ED presentations, } \\
\text { demographic social } \\
\text { and clinical variables }\end{array}$ & Public / Pop'n Hth. & Adequate \\
\hline $\begin{array}{l}\text { Ryan et al } \\
(1997)\end{array}$ & UK & Experiential Narrative & $\mathrm{N} / \mathrm{A}$ & $\begin{array}{l}\text { Psychiatry/ } \\
\text { Nursing }\end{array}$ & Adequate \\
\hline $\begin{array}{l}\text { Spurrell et al } \\
(2003)\end{array}$ & UK & Quantitative - Retrospective data analysis & $\begin{array}{l}\text { Health of the Nation } \\
\text { Outcome Scale, } \\
\text { Global Ass't of } \\
\text { Functioning }\end{array}$ & $\begin{array}{l}\text { Mental Health/ } \\
\text { Psychiatry }\end{array}$ & Intermediate \\
\hline $\begin{array}{l}\text { Thienhaus et } \\
\text { al (2004) }\end{array}$ & USA & $\begin{array}{l}\text { Experiential Narrative and } \\
\text { Theoretical Analysis } \\
\end{array}$ & N/A & Psychiatry/Medical & Intermediate \\
\hline Tyuse (2012) & USA & $\begin{array}{l}\text { Quantitative \& Qualitative - } \\
\text { Retrospective data analysis, Review of } \\
\text { intervention }\end{array}$ & N/A & Social Work & Intermediate \\
\hline
\end{tabular}




\begin{tabular}{|l|l|l|l|l|l|}
\hline $\begin{array}{l}\text { Wand et al } \\
(2010)\end{array}$ & Australia & $\begin{array}{l}\text { Literature Review and Theoretical } \\
\text { Analysis }\end{array}$ & N/A & Nursing & Adequate \\
\hline $\begin{array}{l}\text { Wand et al } \\
(2011)\end{array}$ & Australia & Quantitative - Retrospective data analysis & $\begin{array}{l}\text { K-10, General Self } \\
\text { Efficacy Scale }\end{array}$ & Nursing & Adequate \\
\hline $\begin{array}{l}\text { Wells et al } \\
(2013)\end{array}$ & USA & Quantitative \& Qualitative & PHQ-9 & $\begin{array}{l}\text { Mental Health/ } \\
\text { Psychiatry/ } \\
\text { Social Work }\end{array}$ & Intermediate \\
\hline
\end{tabular}

* Composite indicator of quality and relevance to the specific area of this review question

\section{Copyright Disclaimer}

Copyright reserved by the author(s).

This article is an open-access article distributed under the terms and conditions of the Creative Commons Attribution license (http://creativecommons.org/licenses/by/3.0/). 